\title{
Computer Program
}

National Cancer Institute

\section{Source}

National Cancer Institute. Computer Program. NCI Thesaurus. Code C17146.

A set of coded instructions, which a computer follows in processing data, performing an operation, or solving a logical problem, upon execution of the program. 